\title{
Curvas de crescimento e destruição térmica de sorovares de Salmonella sp. isolados de lingüiça frescal de carne suína
}

\author{
Growth and death curves of Salmonella serovars isolated from fresh pork sausages \\ Lisandra Mürmann, Maria Cecília Magagnin dos Santos \& Marisa Cardoso
}

\begin{abstract}
RESUMO
Análises conduzidas em produtos de origem suína têm encontrado a ocorrência de Salmonella sp. em baixas contagens. Entretanto, fatores relacionados ao armazenamento e preparo dos alimentos podem influenciar a população de Salmonella sp. presente no alimento, determinando que doses suficientes para causar infecção alimentar sejam atingidas. Desta forma, para a condução de uma análise de risco, essas variáveis precisam ser estudadas. O objetivo deste trabalho foi avaliar a cinética de crescimento e destruição de isolados de Salmonella encontrados em lingüiça frescal de carne suína. Foram utilizados isolados de doze sorovares distintos de Salmonella, os quais após cultivados em caldo nutriente foram ajustados até uma concentração de $4 \log _{10}$ para os ensaios de crescimento e $8 \log _{10}$ para inativação térmica. Os ensaios de crescimento foram conduzidos na temperatura ambiente $\left(22-33^{\circ} \mathrm{C}\right)$ e de refrigeração $\left(6-11^{\circ} \mathrm{C}\right)$, enquanto a destruição térmica foi avaliada a $60^{\circ} \mathrm{C}$. Após diferentes intervalos de tempo na temperatura ambiente (0-10 horas); refrigeração (0-30 dias) e temperatura de destruição (0-30 minutos) foram retiradas alíquotas e realizadas contagens pelo método de Miles-Minsra. A cinética de crescimento em temperatura ambiente foi semelhante para os diferentes sorovares. Até duas horas todos os sorotipos permaneceram em fase lag e, após, iniciou-se a fase exponencial. Em temperatura de refrigeração, todos os isolados apresentaram o mesmo comportamento, mantendo a contagem inicial até 30 dias. A destruição térmica ocorreu após o tempo de 20 minutos em todos os ensaios. Os resultados obtidos neste trabalho indicam que isolados dos diferentes sorovares de Salmonella analisados apresentam cinética de crescimento e de destruição térmica semelhante.
\end{abstract}

Descritores: Salmonella, temperatura, cinética de crescimento, cinética de destruição.

\section{ABSTRACT}

Low counts of Salmonella sp. has been detected in assays conducted with pork products. However, storage condition and food preparation can affect Salmonella populations in contaminated foods, allowing the multiplication until the infectious dose level. For this reason, the aforementioned variables must be included in food risk analysis. The aim of this study was to evaluate the growth and death curves of Salmonella isolates from fresh pork sausages. Isolates belonging to twelve Salmonella serovars were grown in nutrient broth and diluted until a concentration of $4 \log _{10}$ or $8 \log _{10}$ for the growth assays and heat destruction test, respectively. The growth curve was determinate at room temperature $\left(22-33^{\circ} \mathrm{C}\right)$ and under refrigeration $\left(6-11^{\circ} \mathrm{C}\right)$, while the death curve was evaluated at $60^{\circ} \mathrm{C}$. After different intervals at room temperature $(0-10 \mathrm{~h})$, under refrigeration $(0-30$ days) and at $60^{\circ} \mathrm{C}(0-30 \mathrm{~min})$, aliquots were taken from each assay for bacterial enumeration using the Miles-Minsra method. At room temperature, all Salmonella serovars started the exponential phase after a two hours period in lag phase. Under refrigeration all isolates presented the initial population counts up to 30 days. The heat destruction was observed after $20 \mathrm{~min}$ in all assays. The results indicated that isolates belonging to the analyzed Salmonella serovars present similar growth and heat destruction curves.

Key words: Salmonella, temperature, growth curve, heat death curve. 


\section{INTRODUÇÃO}

Salmonella sp. é um importante contaminante de alimentos, principalmente de origem animal, e é um dos principais agentes bacterianos responsáveis por toxinfecções em muitos países [11,13]. Segundo dados da Secretaria Estadual da Saúde no Estado do Rio Grande do Sul, desde 1993, a salmonelose tem sido a doença transmitida por alimentos de maior ocorrência [6,17]. Apesar da maioria dos surtos estar relacionada com alimentos contendo ovos [3,17], produtos de origem suína podem ser igualmente veiculadores de Salmonella [2]. O risco de desenvolver salmonelose pelo consumo de um alimento é influenciado por diversos fatores, entre eles a quantidade de Salmonella sp. presente e práticas de armazenamento e preparo do alimento [3,20]. O binômio tempo/temperatura ao qual o alimento está exposto, associado à velocidade de crescimento do isolado bacteriano, pode determinar que o alimento contaminado, no momento da ingestão, apresente contagens de Salmonella sp. capazes de causar infecção [5]. Dessa forma, para a avaliação do risco que um alimento representa deve-se levar em consideração a influência que eventos que propiciem a multiplicação e a destruição da bactéria exercerá sob a dose infectante presente no momento da ingestão desse alimento. Como uma das etapas para a análise desse risco, o objetivo desse trabalho foi avaliar a curva de crescimento, em temperatura ambiente e de refrigeração e a inativação térmica de sorovares de Salmonella isolados de lingüiça frescal de carne suína.

\section{MATERIAIS E MÉTODOS}

Foram utilizados isolados de doze sorovares distintos de Salmonella sp. (Brandenburg, Panama, Derby, Typhimurium, Agona, Senftenberg, Schwarzengrund, Infantis, Ohio, Orion, Cerro e Muenster), oriundos de lingüiça frescal suína. Alíquotas (1mL) de culturas de 24 horas em Infusão Cérebro e Coração (BHI) de cada isolado foram diluídas seriadamente em água peptonada $0,1 \%$, em triplicata. Para os ensaios de crescimento utilizou-se a concentração de $4 \log _{10}$ e para inativação térmica $8 \log _{10^{\circ}}$. As amostras mantidas á temperatura ambiente $\left(22-33^{\circ} \mathrm{C}\right)$ foram monitoradas após os tempos de 0, 2, 4, 6, 8 e 10 horas. As armazenadas sob refrigeração (6-1 $1{ }^{\circ} \mathrm{C}$ ) foram verificadas nos dias $0,1,10,20,30$. Nos ensaios de destruição térmica em banho-maria $\left(60^{\circ} \mathrm{C}\right)$ foram utilizados os intervalos de $0,1,2,5,10,15$, 20,25 e 30 minutos. A cada um dos referidos tempos, alíquotas dos ensaios realizados foram semeadas, em triplicata, em Ágar Triptose de Soja (TSA), pelo método de plaqueamento em gotas [15]. Foram calculadas as médias das repetições obtidas para cada sorovar, utilizando o programa Microsoft Office Excel.

\section{RESULTADOS}

A partir da população inicial de $4 \log _{10}$, a cinética de crescimento em temperatura ambiente foi semelhante para todos os sorovares. Até duas horas todos os isolados permaneceram em fase lag e, a partir desse período, iniciou-se a fase exponencial. Nas 6 horas a contagem esteve entre 5-7 $\log _{10}$ e, após $10 \mathrm{~h}$, alcançou 7-8 $\log _{10}$ (Figura 1A). Em temperatura de refrigeração, os isolados de todos os sorovares mantiveram a contagem inicial até os 30 dias (Figura 1B).

Em relação aos resultados obtidos na curva de destruição térmica, a partir da população inicial de 7-8 $\log _{10}$, todos os sorovares de Salmonella submetidos á temperatura de $60^{\circ} \mathrm{C}$, foram totalmente inativados após o tempo de 20 minutos (Figura 1C).

\section{DISCUSSÃO}

Estudo anterior demonstrou que baixas contagens de Salmonella sp. podem estar presentes em lingüiça frescal de carne suína [16]. Desta forma, o risco que esse produto oferece ao consumidor estará relacionado à existência de condições que permitam a multiplicação da bactéria no alimento. Nesse contexto, o estudo da cinética de crescimento do microrganismo é de grande importância [18] uma vez que um alimento será submetido a fatores extrínsecos variáveis que influenciarão na sua sobrevivência. Ao lado disso, o parâmetro de crescimento obtido para as populações de microrganismos pode diferir [12]. Dessa forma, para as simulações necessárias para a análise do risco que o consumo de lingüiça frescal de carne suína pode oferecer para a ocorrência de salmonelose, os diversos sorovares de Salmonella encontrados nesse produto foram analisados quanto ao seu comportamento quando submetidos a diferentes temperaturas.

Em temperatura ambiente, os diferentes isolados apresentaram comportamento semelhante iniciando a multiplicação após duas horas. Tempo de duração semelhante na fase lag havia sido observado em isolados dos sorovares Enteritidis, Bredeney e 

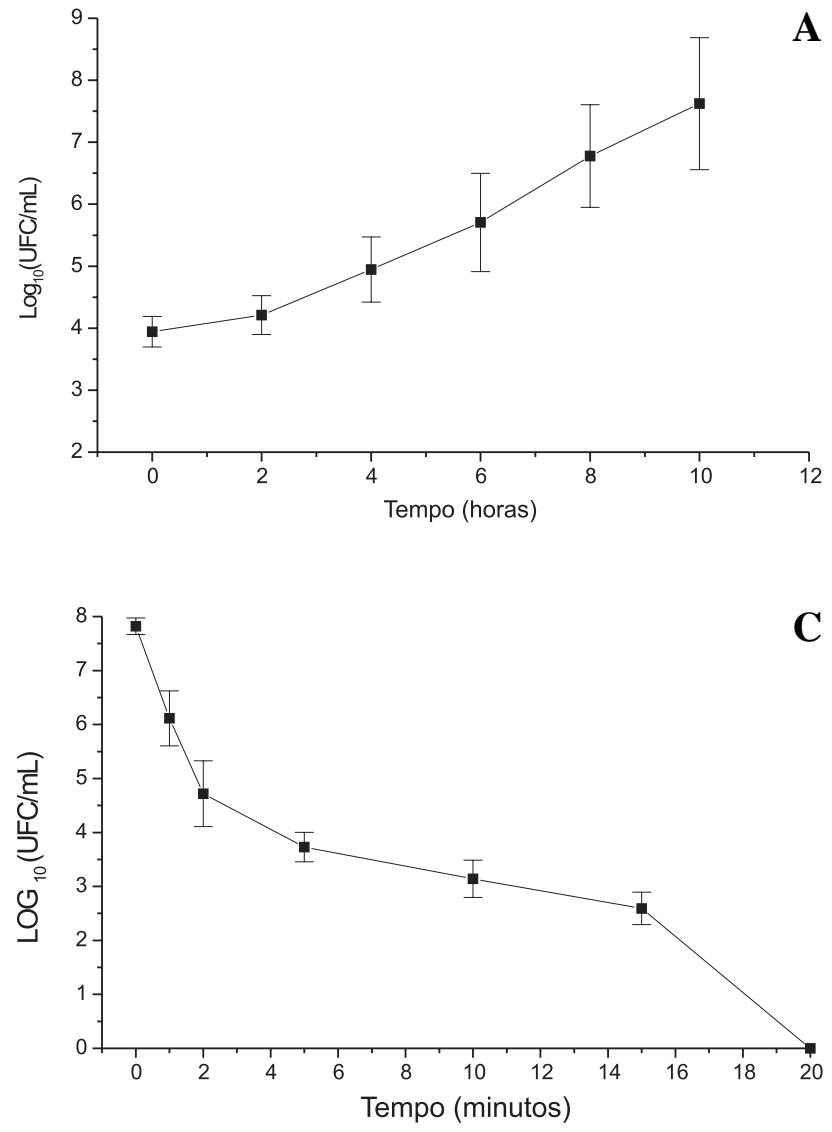

Typhimurium, seguido de uma fase exponencial que durou aproximadamente 12 horas [14]. Da mesma forma, esse período de fase lag justifica dados anteriores [3] demonstrando que mais de $20 \%$ das toxinfecções alimentares ocorridas no Rio Grande do Sul, entre 1997 e 1999, foram causadas pelo armazenamento dos alimentos em temperatura ambiente por mais de duas horas. Também considerando que a fase lag das bactérias é curta, a RDC 216 [1] institui que produtos perecíveis devem ser expostos à temperatura ambiente somente pelo tempo mínimo necessário, a fim de não comprometer a qualidade higiênicosanitária do alimento.

Por outro lado, quando os isolados foram mantidos em temperatura de refrigeração, como preconiza a legislação, a população de Salmonella manteve-se constante pelos 30 dias de observação. Em condições de baixas temperaturas, as reações químicas, a atividade enzimática e a multiplicação dos microrganismos são mais lentas, levando a um maior tempo em que os alimentos poderão ser armazenados antes do seu consumo [10,19]. Entretanto, o armazenamento sob refrigeração não resultou na diminuição das populações de Salmonella sp., demonstrando que, uma

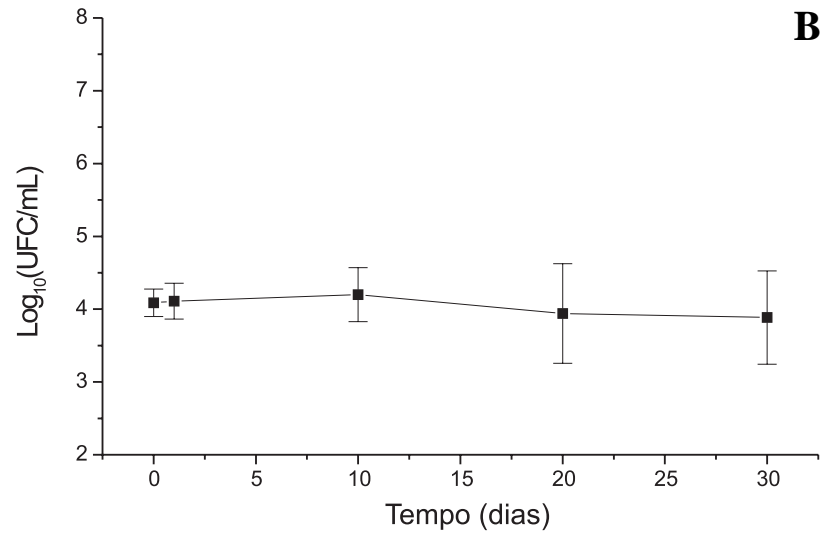

Figura 1. Curva de crescimento médio de isolados dos sorovares Brandenburg, Panama, Derby, Typhimurium, Agona, Senftenberg, Schwarzengrund, Infantis, Ohio, Orion, Cerro e Muenster de Salmonella, em água peptonada $0,1 \%$, na temperatura ambiente (1A), sob refrigeração (1B) e destruição térmica (1C).

vez contaminado, o alimento poderá representar risco durante toda sua vida de prateleira.

A dose infectante de Salmonella para humanos saudáveis varia entre $10^{6}$ e $10^{8}$ unidades formadoras de colônia (UFC), embora já tenham sido relatados casos de salmonelose com doses inferiores [9]. Neste estudo, a dose infectante foi alcançada após período de 6-8 horas na temperatura ambiente, demonstrando que mesmo os alimentos com uma população inicial reduzida de Salmonella, poderão ser potenciais causadores de toxinfecção alimentar, caso tenham um armazenamento prolongado na temperatura de risco.

A maioria da população costuma consumir a lingüiça frescal após a cocção, sendo importante, para compor as simulações da análise de risco, o conhecimento da cinética de destruição do microrganismo. A população inicial adotada no estudo de destruição térmica esteve acima daquela considerada como dose infectante, bem como das contagens encontradas em amostras de lingüiça frescal [16]. Entretanto, no presente estudo simulações de armazenamento inadequado, anterior ao tratamento térmico, demonstraram o aumento expressivo da população inicial. Por conta 
disso, o experimento de inativação térmica partiu de um cenário mais adverso, onde as contagens iniciais teriam sido ampliadas em mais de $5 \log _{10}$. Mesmo nessas condições, porém, após 20 minutos numa temperatura inferior ao preconizado pela RDC 216 [1] a ser atingida no centro geométrico do alimento $\left(70^{\circ} \mathrm{C}\right)$, houve a completa inativação de todos os isolados pertencentes aos sorovares de Salmonella provenientes desse tipo de alimento. Este resultado é semelhante ao encontrado para $S$. Enteritidis [14], onde uma população inicial de 6-7 $\log _{10}$ foi destruída em 15 minutos. Porém o tempo encontrado foi superior ao reportado por outros autores para uma população de $5 \log _{10}$ de $S$. Enteritidis [8]. Deve-se considerar, ainda, que a condução do experimento no presente estudo em água peptonada não incluiu na simulação a proteção que a matriz do alimento pode oferecer contra a inati- vação térmica da bactéria. Desta forma, num próximo passo da análise de risco, a matriz do alimento deverá ser incluída na simulação.

Finalmente, mesmo considerando a destruição que a bactéria sofrerá durante o tratamento térmico do alimento, riscos como a contaminação cruzada $[4,7]$ de outros alimentos em contato com a mesma superfície de preparo onde esteve a lingüiça frescal contaminada, bem como a recontaminação desse alimento, após o tratamento térmico, não podem ser esquecidos.

\section{CONCLUSÃO}

Os resultados obtidos neste trabalho indicam que isolados dos diferentes sorovares encontrados na lingüiça frescal suína apresentam cinética de crescimento e destruição térmica semelhante.

\section{REFERÊNCIAS}

1 Brasil. 2004. Resolução-RDC n. 216, de 15 de setembro de 2004 da Agência Nacional de Vigilância Sanitária (ANVISA). Dispõe sobre Regulamento Técnico de Boas Práticas para Serviços de Alimentação. Diário Oficial da União, DF, 16 set.

2 Cantoni C., D’Aubert S. \& Traldi C. 1993. Serotipi di Salmonella nell'uomo e negli alimenti nel triennio 1988-1991 in Itália. Archivio Veterinário Italiano. 44 (Suppl): 1-14.

3 Costalunga S. \& Tondo E.C. 2002. Salmonellosis in Rio Grande do Sul, 1997 to 1999. Brazilian Journal of Microbiology. 33:342-346.

4 Escartín E.F., Lozano J.S. \& Garcia O.R. 2000. Quantitative survival of native Salmonella serovars during storage of frozen raw pork. International Journal of Food Microbiology. 54: 19-25.

5 Forsythe S.J. 2002. Microbiological Risk Assessment of Food. USA: Blackwell publishing, 212p.

6 Fundação Estadual de Pesquisa e Produção em Saúde. Instituto de Pesquisa Brasileira/Laboratório Central do Rio Grande do Sul (FEPPS/IPB/LACEN). 1999. Relatório de Investigações de surtos de Salmonelose de 1984 a 1999.

7 Gorman R., Bloomfield S. \& Adley C.C. 2002. A study of cross-contamination of food-borne pathogens in the domestic kitchen in the Republic of Ireland. International Journal of Food Microbiology. 76:143-150.

8 Humpheson L., Adams M.R., Anderson W.A. \& Cole M.B. 1998. Biphasic thermal inactivation kinetics in Salmonella Enteritidis PT4. Applied Environmental Microbiology. 64: 459-464.

9 Humphrey T.J. 2004. Salmonella, stress responses and food safety. Science and Society. 2: 504-509.

10 Instituto Nacional de Metrologia, Normalização e Qualidade Industrial (INMETRO). 1996. Relatório da medição de temperatura em freezers de supermercados. Rio de Janeiro.

11 Laconha I., Bagessen D.L., Rementeria A. \& Garaizar J. 2000. Genotypic characterization by PFGE of Salmonella enterica serotype Enteritidis phage types 1, 4, 6, and 8 isolated from animal and human sources in three European countries. Veterinary Microbiology. 75:155-165.

12 Liu F., Yang R.Q. \& Li Y.F. 2006. Correlations between growth parameters of spoilage micro-organisms and shelf-life of pork stored under air and atmosphere at -2.4 and $10^{\circ} \mathrm{C}$. Food Microbiology. 23: 578-583.

13 Lopalco P.L., Germinario C., Di Martino V., Frisoli L., Pagano A., Quarto M. \& Barbuti S. 2000. Epidemiologic study and cost analysis of an Salmonella Enteritidis epidemic. Annali d'igiene. 12: 279-285.

14 Malheiros P.S. 2007. Avaliação da cinética de crescimento, resistência ácida e resistência térmica de Salmonella Enteritidis envolvida em surtos alimentares ocorridos no Rio Grande do Sul e comparação com outros sorovares. 86f. Porto Alegre, RS. Dissertação (Mestrado em Ciência e Tecnologia de Alimentos) - Programa de Pós-Graduação em Ciência e Tecnologia de Alimentos, Universidade Federal do Rio Grande do Sul.

15 Milles A.A.L. \& Misra S.S. 1938. The estimation of the bacterial power of the blood. Journal of. Hygiene. 38:732-749. 
16 Mürmann L., Santos M.C. \& Cardoso M. 2005. Prevalence and level of Salmonella enterica in pork fresh sausages purchased in southern Brazil. In: Proceedings of 13 S International Symposium Salmonella and Salmonellosis (SaintMalo, França). p. 443-444.

17 Nadvorny A., Figueiredo D.M.S. \& Schmidt V. 2004. Ocorrência de Salmonella sp. em surtos de doenças transmitidas por alimentos no Rio Grande do Sul, em 2000. Acta Scientiae Veterinariae . 32: 47-51.

18 Perni S., Andrew W.P. \& Shama G. 2005. Estimating the maximum growth rate from microbial growth curve: definition is everything. Food Microbiology. 22: 491-495.

19 Thomson J.E., Whitehead W.K. \& Mercuri A.J. 1974. Chilling poultry meat- a literature review. Poultry Science.53:12681281.

20 Wegener H.C. \& Bager F. 1997. Pork as a source of human salmonelosis.. In: Proceedings of the International Symposium on Epidemiology and Control of Salmonella in Pork, v.2. (Copenhagen, Dinamarca). pp.3-8. 